\title{
Stability Profiles of Drug Products Extended beyond Labeled Expiration Dates
}

\author{
ROBbe C. LYON, ${ }^{1}$ Jeb S. TAYLOR, ${ }^{1}$ DONNA A. PORTER, ${ }^{2}$ HULlahAlLI R. PRASANNA, ${ }^{1}$ AJAZ S. HUSSAIN ${ }^{3}$ \\ ${ }^{1}$ Division of Product Quality Research, Center for Drug Evaluation and Research, Food and Drug Administration, \\ HFD-941, White Oak, Life Sciences Building 64, 10903 New Hampshire Avenue, Silver Spring, Maryland 20993-0002 \\ ${ }^{2}$ Division of Field Science, Office of Regional Operations, Office of Regulatory Affairs, Food and Drug Administration, \\ Rockville, Maryland 20857 \\ ${ }^{3}$ Vice President \& Global Head of Biopharmaceutical Development, Sandoz, 506 Carnegie Center, Princeton, \\ New Jersey 08540
}

Received 6 January 2006; accepted 17 March 2006

Published online in Wiley InterScience (www.interscience.wiley.com). DOI 10.1002/jps.20636

\begin{abstract}
The American Medical Association has questioned whether expiration dating markedly underestimates the actual shelf life of drug products. Results from the shelf life extension program (SLEP) have been evaluated to provide extensive data to address this issue. The SLEP has been administered by the Food and Drug Administration for the United States Department of Defense (DOD) for 20 years. This program probably contains the most extensive source of pharmaceutical stability data extant. This report summarizes extended stability profiles for 122 different drug products (3005 different lots). The drug products were categorized into five groups based on incidence of initial extension failures and termination failures (extended lot eventually failed upon re-testing). Based on testing and stability assessment, $88 \%$ of the lots were extended at least 1 year beyond their original expiration date for an average extension of 66 months, but the additional stability period was highly variable. The SLEP data supports the assertion that many drug products, if properly stored, can be extended past the expiration date. Due to the lot-to-lot variability, the stability and quality of extended drug products can only be assured by periodic testing and systematic evaluation of each lot. (c) 2006 Wiley-Liss, Inc. and the American Pharmacists Association J Pharm Sci 95:1549-1560, 2006
\end{abstract}

Keywords: shelf life; drug stability; shelf life extension program; SLEP; expiration date

\section{INTRODUCTION}

The concern that expiration dating may markedly underestimate the actual shelf life of drug products has been an issue. ${ }^{1-3}$ The American Medical Association (AMA) recently reviewed the procedures for setting pharmaceutical expiration dates and the clinical and fiscal consequences of setting such dates. ${ }^{4}$ The AMA concluded that the actual shelf lives of some products are greater

Correspondence to: Robbe C. Lyon (Telephone: 301-7960019; Fax: 301-796-9816; E-mail: robbe.lyon@fda.hhs.gov)

Journal of Pharmaceutical Sciences, Vol. 95, 1549-1560 (2006) (C) 2006 Wiley-Liss, Inc. and the American Pharmacists Association than their labeled expiration dates and acknowledged that best evidence to support this resides in the shelf life extension program (SLEP). Smaller studies have addressed the long-term stability of drug products ${ }^{5,6}$ and drug substances. ${ }^{7}$ One study determined that four products, captopril tablets, flucloxacillin capsules, cefoxitin injection, and theophylline tablets stored under ambient temperatures maintained at least $98 \%$ of label claim for drug content for 18-170 months past the labeled expiration dates. ${ }^{5}$ In a modification to the AMA Policy H-115.983, the pharmaceutical industry, the Food and Drug Administration (FDA) and the United States Pharmacopeia 
(USP) were urged to determine the benefits and risks associated with lengthening expiration dates and to subsequently conduct longer stability testing. In response, all of the data from the SLEP was reviewed and analyzed. As a retrospective analysis, this report summarizes extended drug product stability data collected by the SLEP over the past 20 years.

The International Conference on Harmonization (ICH) defines shelf life as "the time period which a drug product is expected to remain within the approved shelf life specification, provided that it is stored under conditions defined on the container label."8 It is expected that the actual shelf life will slightly exceed the projected labeled shelf life. Pharmaceutical manufacturers are required to assign an expiration date to each drug product marketed in the United States. The labeled shelf life is estimated using appropriate stability testing (21 CFR 211.137 and 211.166) under current good manufacturing practices as established and monitored by the FDA. The stability assessments of both the new drug substance and the new drug product stored under controlled conditions are required documentation for submission to the FDA in a new drug application (NDA). The assessment follows scientifically based technical procedures as described in the ICH Q1A(R2) Guidance. ${ }^{8}$ The initial expiration date is based on the amount of real-time stability data (generally from pilot scale batches) for the drug product available at the time of approval of the NDA. This initial date may later be extended contingent upon the receipt of acceptable supporting data from the manufacturer based on accelerated stability studies and actual real-time stability data collected from the first three production batches. Drug products marketed in the United States generally have a labeled shelf life of 12 60 months.

The SLEP is administered by the FDA for the U.S. DOD ${ }^{9}$ and recently for the Strategic National Stockpile (SNS). To maintain a state of readiness, the military maintains, under controlled conditions, large stockpiles of pharmaceuticals sealed in their original container closures. A system of extending the functional shelf life of these drug products beyond their original expiration date was initiated to reduce the high cost of replacing these stockpiles. Based on a comprehensive testing program, the shelf life of several drug products has been extended on a lot-by-lot basis. This program has resulted in substantial savings to the military. In return the FDA has access to a valuable source of long-term stability data for a variety of drug products.

This report summarizes data for 3005 lots representing 122 drug products generated by the SLEP since 1986. Based on stability assessment, $88 \%$ of the lots were extended beyond their original expiration date. Of the 2652 lots extended, only $18 \%$ were eventually terminated due to failure. The rest of the lots are either still active $(35 \%)$ or were abated (47\%) by the military. The shelf life extension results were summarized in tabular form. The products were arranged into groups based on stability performance.

\section{MATERIALS AND METHODS}

\section{SLEP Program Operation}

The SLEP is a key component of the Medical Readiness Strategic Plan as developed by the DOD Health Affairs and the Military Medical Departments. The DOD Defense Medical Standardization Board (DMSB) oversees the SLEP program and acts as an interface between the military services and the FDA. Pharmaceutical drug products sealed in original container closures are stored under controlled conditions by the military services. Certain lots of drug product that are approaching their labeled expiration date are selected by the DMSB for participation in the SLEP program. Representative sealed containers of drug product from a given lot are submitted to the FDA SLEP coordinator in the Office of Regulatory Affairs for testing by the FDA field labs. The test results are transmitted through the FDA SLEP coordinator to the FDA SLEP chemist in the Division of Product Quality Research (DPQR), Center for Drug Evaluation and Research (CDER) for analysis. The FDA SLEP chemist evaluates the test results, approves or rejects the extension of the shelf life for that lot and archives the data, evaluations, and approvals for the program. Approval for a new expiration date for that lot of drug product is transmitted through the FDA SLEP coordinator to representatives for the DMSB.

\section{Sample Testing}

Sealed containers of drug product from a given lot are sent to an FDA field lab. Samples are subjected to a battery of tests prescribed by the FDA SLEP chemist. These tests and 
specifications are based on compendial (USP) product release tests or the product release tests as described in the original FDA submission (NDA). If a lot fails any specification based on the battery of tests, then the shelf life for that lot is expired.

\section{Predicting Extended Shelf Life}

Extending the shelf life is based on developing a history of real-time stability data for each lot of drug product. This data is compiled by continual testing within the SLEP. Test results from each retest project form a set of real-time data. That real-time data is evaluated and an updated expiration period for that lot of drug product is predicted using regression analysis. Each retest attribute generates a particular remaining expiration period. If each remaining expiration period predicted is longer than 1 year, the lot of drug product is granted a new expiration date. An "initial extension failure" indicates that the lot could not be extended past original expiration date. A "termination failure" indicates that a previously extended lot eventually fails upon retesting and based on regression analysis predictions, cannot be extended for an additional year.

\section{Product Quality Attributes}

The attributes tested for a drug product varied depending on the dosage form. For solid oral drug products, the attributes were potency (assay), impurities, water content, dissolution, and physical appearance. For reconstituted dry powders, the attributes were potency, $\mathrm{pH}$, water content, and physical appearance. For injectable solutions, the attributes were potency, impurities, $\mathrm{pH}$, preservatives, and physical appearance (color, particulates). For creams and ointments, the attributes were potency, $\mathrm{pH}$, and physical appearance. For autoinjectors, the attributes were potency (assay), degradants, $\mathrm{pH}$, preservatives, injection mechanics, and physical appearance.

\section{RESULTS}

The 122 drug products evaluated by this study were categorized into five groups (see Tab. 1) based on shelf life extension data (relative number of lots initially extended and number of extended lots terminated). For the products assigned to Groups 1 and 2, all lots were extended beyond their original expiration date. The products assigned to Groups 3, 4, and 5 had some lots that were denied initial extension. Overall, 2650 $(88 \%)$ of the 3005 lots were extended past their original expiration date for an average of 66 months. Of these, 934 lots (35\%) are still active and were granted an average extension of 62 months, 1237 lots (47\%) were abated before failure (dormant) after an average extension of 70 months, and 479 lots (18\%) were terminated due to failure after an average extension of 65 months. Of the 479 lots that eventually failed, no lots failed before 1 year and 312 lots were extended beyond 4 years.

The 63 products assigned to Group 1 were further divided into subclasses based on the number of lots tested for each product. For these products, none of the extended lots were terminated due to failure (periodic retest). Each of the 15 products assigned to Group 1A (Tab. 2) had at least 10 lots evaluated. Of the 466 lots tested, 284 lots (primarily 205 lots of ciprofloxacin tablets) are still active in the program and available for use. The average extension for these active lots was 52 months. The remaining 182 lots were not further tested or extended and are categorized as dormant. The average extension for these dormant lots was 67 months. The average extension time for

Table 1. Group Assignment

\begin{tabular}{lcccccc}
\hline Group & $\begin{array}{c}\text { Number of } \\
\text { Products }\end{array}$ & $\begin{array}{c}\text { Number of Lots } \\
\text { per Product }\end{array}$ & $\begin{array}{c}\text { Total Lots } \\
\text { Tested }\end{array}$ & $\begin{array}{c}\text { Number of Lots } \\
\text { Initially Extended }\end{array}$ & $\begin{array}{c}\text { Number of Extended } \\
\text { Lots Terminated }\end{array}$ & $\begin{array}{c}\text { Average Extension Time } \\
\text { for Extended Lots (mo.) }\end{array}$ \\
\hline 1A & 15 & $10-242$ & 466 & All & None & 58 \\
1B & 25 & $5-9$ & 164 & All & None & 65 \\
$1 \mathrm{C}$ & 23 & $3-4$ & 85 & All & None & 55 \\
2 & 20 & $3-41$ & 254 & All & Some $(41)$ & 58 \\
3 & 13 & $3-169$ & 278 & Most $(256)$ & None & 76 \\
4 & 16 & $8-687$ & 1675 & Most (1402) & Some $(431)$ & 38 \\
5 & 10 & $2-21$ & 83 & $\leq 50 \%(23)$ & Some $(7)$ & 66 \\
Total & 122 & $2-687$ & 3005 & 2650 & 479 & \\
\hline
\end{tabular}


Table 2. Group 1A: Products With No Failures ( $\geq 10$ Lots tested)

\begin{tabular}{|c|c|c|c|c|c|c|}
\hline \multirow[b]{2}{*}{ Drug Product } & \multirow[b]{2}{*}{ Dosage Form } & \multicolumn{3}{|c|}{ Number of Lots } & \multicolumn{2}{|c|}{ Extension Time (mo.) } \\
\hline & & Tested & Dormant & Active & Mean & Range \\
\hline Amoxicillin sodium & Tablets & 21 & 0 & 21 & 23 & $22-23$ \\
\hline Ciprofloxacin & Tablets & 242 & 37 & $205^{f}$ & 55 & $12-142$ \\
\hline Diphenhydramine $\mathrm{HCl}$ & Syringe-needle ${ }^{a}$ & 12 & 12 & 0 & 76 & $33-126$ \\
\hline Doxycycline hyclate & Capsules $^{b}$ & 13 & 3 & $10^{g}$ & 50 & $37-66$ \\
\hline Doxycycline hyclate & Powder ${ }^{b}$ & 31 & 1 & $30^{h}$ & 27 & $14-52$ \\
\hline Halothane & Liquid & 12 & 12 & 0 & 67 & $51-92$ \\
\hline Mannitol & Injection-solution & 10 & 10 & 0 & 66 & $21-109$ \\
\hline Morphine sulfate & Syringe-needle ${ }^{c}$ & 13 & 11 & $2^{i}$ & 89 & $35-119$ \\
\hline Naloxone $\mathrm{HCl}$ & Injection-solution & 10 & 10 & 0 & 77 & $60-95$ \\
\hline Oxacillin sodium & Powder & 13 & 13 & 0 & 56 & $28-116$ \\
\hline Potassium iodide & Tablets $^{d}$ & 12 & 0 & 12 & 69 & $28-184$ \\
\hline Sodium bicarbonate & Injection-solution & 37 & 37 & 0 & 55 & $14-101$ \\
\hline Sodium chloride & Irrigation $^{e}$ & 16 & 16 & 0 & 72 & $40-108$ \\
\hline Sodium nitrite & Injection-solution & 10 & 7 & $3^{j}$ & 89 & $35-180$ \\
\hline Sodium thiosulfate & Injection-solution & 14 & 13 & $1^{k}$ & 131 & $24-151$ \\
\hline
\end{tabular}

\footnotetext{
${ }^{a}$ See "spray" dosage form (Group 5).

"See "tablet" dosage form (Group 3).

"See "autoinjector" (Group 2) and "injection-solution" (Group 3) dosage forms.

${ }^{d}$ See "granules" dosage form (Group 1B).

"See "injection-solution" dosage form (Group 2).

${ }^{f}$ Active range: $15-142$ months.

${ }^{g}$ Active range: $29-66$ months.

${ }^{h}$ Active range: $14-35$ months.

${ }^{i}$ Active range: $35-54$ months.

${ }^{j}$ Active range: $49-145$ months.

${ }^{k}$ Active range: 49 months.
}

all of the lots from these 15 products was 58 months, ranging from 12 to 184 months. The mean extension times and the ranges of extension times for the individual products are provided in the table. For six of the products the extension times represent a combination of the active and dormant lots. In these cases, the range for the active lots is annotated in the table. Other dosage forms of diphenhydramine HCL, doxycycline hyclate, morphine sulfate, potassium iodide, and sodium chloride were assigned to other groups.

The 25 products assigned to Group 1B (Tab. 3) had 5-9 lots evaluated. Of the 164 lots tested, 143 lots are dormant and 21 lots are still active. The average extension for the dormant lots was 61 months and for the active lots was 92 months. The average extension time for all of the lots from these 25 products was 65 months, ranging from 15 to 278 months. Other dosage forms of ampicillin, cimetidine $\mathrm{HCl}$, ciprofloxacin, potassium iodide, and povidone-iodine were assigned to other groups.

The 23 products assigned to Group 1C (Tab. 4) had only 3-4 lots evaluated. All the 85 lots tested are now dormant. The average extension for these dormant lots was 55 months, ranging from 12 to 114 months. The tablet dosage form of chlorpromazine $\mathrm{HCl}$ was assigned to Group 2.

Each of the 20 products assigned to Group 2 (Tab. 5) had some lots that could not be repeatedly extended, one attribute eventually failing during periodic retest. Of the 254 lots tested, 41 lots eventually failed and were terminated, 211 lots are now dormant and 2 lots are currently active. For the terminated lots, the amount of shelf life extension before the failure ranged from 12 to 103 months with an average of 53 months. Termination was due to a variety of test failures as indicated in the table. The average extension for the 211 dormant lots was 59 months ranging from 15 to 137 months. The mean extension times and the ranges of extension times indicated in the table represent a combination of the terminated, dormant, and active lots. The average extension time for these combined lots was 58 months, ranging from 12 to 137 months. The range of extension times for the two active lots is annotated in the table. Other dosage forms of ampicillin sodium, 
Table 3. Group 1B: Products With No Failures (5-9 Lots Tested)

\begin{tabular}{|c|c|c|c|c|c|c|}
\hline \multirow[b]{2}{*}{ Drug Product } & \multirow[b]{2}{*}{ Dosage Form } & \multicolumn{3}{|c|}{ Number of Lots } & \multicolumn{2}{|c|}{ Extension Time (mo. } \\
\hline & & Tested & Dormant & Active & Mean & Range \\
\hline Ampicillin & Capsules $^{a}$ & 5 & 3 & $2^{f}$ & 49 & $22-64$ \\
\hline Amyl nitrite & Inhalant & 6 & 6 & 0 & 59 & $37-76$ \\
\hline Atropine sulfate-pralidoxime chloride & Autoinjector & 5 & 0 & 5 & 31 & $25-38$ \\
\hline Calcium chloride & Injection-solution & 8 & 8 & 0 & 81 & $66-106$ \\
\hline Calcium glucepate & Injection-solution & 8 & 8 & 0 & 49 & $23-82$ \\
\hline Cephalexin & Capsules & 6 & 6 & 0 & 57 & $28-135$ \\
\hline Cimetidine $\mathrm{HCl}$ & Tablets $^{b}$ & 5 & 5 & 0 & 67 & $59-75$ \\
\hline Ciprofloxacin & Suspension $^{c}$ & 7 & 0 & 7 & 32 & $25-40$ \\
\hline Dexamethasone sodium phosphate & Syringe-needle & 7 & 7 & 0 & 61 & $24-93$ \\
\hline Enflurane & Liquid & 8 & 8 & 0 & 48 & $15-94$ \\
\hline Ephedrine sulfate & Injection-solution & 5 & 5 & 0 & 46 & $21-80$ \\
\hline Fentanyl citrate & Injection-solution & 6 & 6 & 0 & 84 & $70-96$ \\
\hline Guaifenesin & ER Tablets & 7 & 5 & $2^{g}$ & 85 & $39-122$ \\
\hline Hetastarch in sodium chloride & Injection-solution & 5 & 5 & 0 & 44 & $30-61$ \\
\hline Hexachlorophene cleansing & Emulsion & 8 & 8 & 0 & 81 & $58-106$ \\
\hline Iothalamate meglumine & Injection-solution & 7 & 7 & 0 & 51 & $20-78$ \\
\hline Ketamine $\mathrm{HCl}$ & Injection-solution & 6 & 6 & 0 & 64 & $42-87$ \\
\hline Mebendazole & Tablets & 8 & 8 & 0 & 58 & $28-89$ \\
\hline Meperidine $\mathrm{HCl}$ & Injection-solution & 6 & 6 & 0 & 89 & $32-128$ \\
\hline Phenytoin sodium & Injection-solution & 5 & 5 & 0 & 63 & $29-100$ \\
\hline Potassium iodide & Granules $^{d}$ & 5 & 0 & 5 & 254 & $225-278$ \\
\hline Povidone-iodine & Ointment $^{e}$ & 7 & 7 & 0 & 65 & $35-134$ \\
\hline Promethazine $\mathrm{HCl}$ & Injection-solution & 9 & 9 & 0 & 51 & $28-73$ \\
\hline Triamterene and hydroclorothiazide & Capsules & 6 & 6 & 0 & 19 & $18-19$ \\
\hline Undecylenic Acid and zinc salt & Powder & 9 & 9 & 0 & 68 & $43-82$ \\
\hline
\end{tabular}

${ }^{a}$ See "injection-solution" dosage form (Group 2).

${ }^{b}$ See "injection-solution" dosage form (Group 2).

"See "tablet" dosage form (Group 1A).

${ }^{d}$ See "tablet" dosage form (Group 1A).

eSee "solution" dosage form (Group 4).

$f_{\text {Active range: } 22-23 \text { months. }}$

${ }^{g}$ Active range: $114-122$ months.

chlorpromazine $\mathrm{HCl}$, cimetidine, morphine sulfate, and sodium chloride were assigned to other groups.

Each of the 13 products assigned to Group 3 (Tab. 6) had most lots extended initially $(\geq 50 \%$ occurrence) and none of the extended lots were terminated due to failure (periodic retest). Of the 278 lots tested, 256 lots were extended and 22 lots were denied extension. Of the extended lots, 81 lots are now dormant and 175 lots are currently active (primarily 159 lots of doxycycline hyclate tablets). The average extension for these dormant lots was 74 months and the average extension for these active lots was 30 months. The average extension time for all of the lots from these 13 products was 44 months, ranging from 12 to 216 months. For three products, the extension times represent a combination of the active and dormant lots. In these cases, the range for the active lots is annotated in the table. The reasons for denying the extension of the 22 lots was due to a variety of test failures as indicated in the table. Other dosage forms of atropine sulfate, doxycycline hyclate, and morphine sulfate were assigned to other groups.

Each of the 16 products assigned to Group 4 (Tab. 7) had most lots extended initially $(\geq 50 \%$ occurrence) and some of the extended lots were terminated due to failure (periodic retest). Of the 1675 lots tested, 1402 lots were extended and 273 lots were denied extension. Extension denials were due to a variety of test failures as indicated in the table. Of the extended lots, 431 lots eventually failed and were terminated, 519 lots now dormant and 452 lots are currently active (primarily 119 lots of atropine sulfate autoinjectors and 188 lots of pralidoxime chloride autoinjectors). For the terminated lots, the amount of shelf life extension before the failure ranged from 12 to 266 months with an 
Table 4. Group 1C: Products With No Failures (3-4 Lots Tested)

\begin{tabular}{|c|c|c|c|c|c|c|}
\hline \multirow[b]{2}{*}{ Drug Product } & \multirow[b]{2}{*}{ Dosage Form } & \multicolumn{3}{|c|}{ Number of Lots } & \multicolumn{2}{|c|}{ Extension Time (mo.) } \\
\hline & & Tested & Dormant & Active & Mean & Range \\
\hline Acetaminophen pseudophedrine & Capsules & 3 & 3 & 0 & 24 & $24-24$ \\
\hline Benzonatate & Capsules & 4 & 4 & 0 & 44 & $12-73$ \\
\hline Bretylium tosylate & Injection-solution & 4 & 4 & 0 & 49 & $15-71$ \\
\hline Bupivacaine $\mathrm{HCl}$ & Injection-solution & 3 & 3 & 0 & 88 & $79-95$ \\
\hline Ceftriaxone sodium & Powder & 4 & 4 & 0 & 60 & $44-69$ \\
\hline Chloroquine $\mathrm{HCl}$ & Injection-solution & 4 & 4 & 0 & 64 & $27-98$ \\
\hline Chlorpromazine $\mathrm{HCl}$ & Injection-solution $^{a}$ & 3 & 3 & 0 & 74 & $59-88$ \\
\hline Dextrose $10 \%$ & Injection-solution & 4 & 4 & 0 & 25 & $23-29$ \\
\hline Dextrose and sodium chloride & Injection-solution & 4 & 4 & 0 & 64 & $51-73$ \\
\hline Dobutamine $\mathrm{HCl}$ & Injection-solution & 3 & 3 & 0 & 47 & $29-79$ \\
\hline Edrophonium chloride & Injection-solution & 4 & 4 & 0 & 65 & $33-114$ \\
\hline Erythromycin lactobionate & Powder & 4 & 4 & 0 & 60 & $38-83$ \\
\hline Hydrocortisone sodium succinate & Injection-solution & 3 & 3 & 0 & 43 & $37-56$ \\
\hline Mafenide acetate & Cream & 3 & 3 & 0 & 59 & $56-63$ \\
\hline Mepivacaine $\mathrm{HCl}$ & Cartridge-needle & 3 & 3 & 0 & 41 & $33-45$ \\
\hline Naproxen & Tablets & 4 & 4 & 0 & 52 & $46-62$ \\
\hline Neostigmine methylsulfate & Injection-solution & 4 & 4 & 0 & 60 & $31-78$ \\
\hline Penicillin G benzathine & Suspension & 4 & 4 & 0 & 70 & $61-84$ \\
\hline Phenylephrine $\mathrm{HCl}$ & Injection-solution & 4 & 4 & 0 & 60 & $53-78$ \\
\hline Prochloroperazine edisylate & Injection-solution & 4 & 4 & 0 & 43 & $28-66$ \\
\hline Protamine sulfate & Powder & 4 & 4 & 0 & 64 & $57-77$ \\
\hline Sulfisoxazole & Tablets & 4 & 4 & 0 & 56 & $45-68$ \\
\hline Tubocurarine chloride & Injection-solution & 4 & 4 & 0 & 59 & $47-69$ \\
\hline
\end{tabular}

${ }^{a}$ See "tablet" dosage form (Group 2).

average of 67 months. Termination was due to a variety of test failures as indicated in the table. The range of extension times for the active lots is annotated in the table. The average extension for these dormant lots was 81 months and the average extension for these active lots was 79 months. The average extension time for all of the lots (terminated, dormant, and active) from these 16 products was 76 months, ranging from 12 to 266 months. The ointment dosage form of povidone-iodine was assigned to Group 1B.

Each of the 10 products assigned to Group 5 (Tab. 8) had most of the lots denied initial extension ( $\geq 50 \%$ occurrence) and some of the extended lots were terminated due to failure (periodic retest). Of the 83 lots tested, 23 lots were extended and 60 lots were denied extension. Extension denials were due to a variety of test failures as indicated in the table. Of the extended lots, 7 lots eventually failed and were terminated, 16 lots are now dormant, and none of the lots are currently active. For the terminated lots, the amount of shelf life extension before the failure ranged from 17 to 94 months with an average of 49 months. Termination was due to a variety of test failures as indicated in the table. The average extension for the 16 dormant lots was 33 months. The average extension time for all of the lots (terminated and dormant) from these 10 products was 38 months, ranging from 14 to 94 months. For the individual products, the mean extension times and the ranges of extension times in the table represent a combination of the terminated and dormant lots. The spray dosage form of diphenhydramine $\mathrm{HCl}$ was assigned to Group 1A.

\section{DISCUSSION}

\section{Performance Evaluation}

Each product tested was assigned to one of five groups (as listed in Tab. 1) based on an explicit classification system. Products with no failures (initial extension failure or termination failure) were assigned to Group 1. This does not imply that these products will be stable indefinitely. Based on past performance, these products may be considered the best candidates for shelf life extension. Other factors, including the number of 


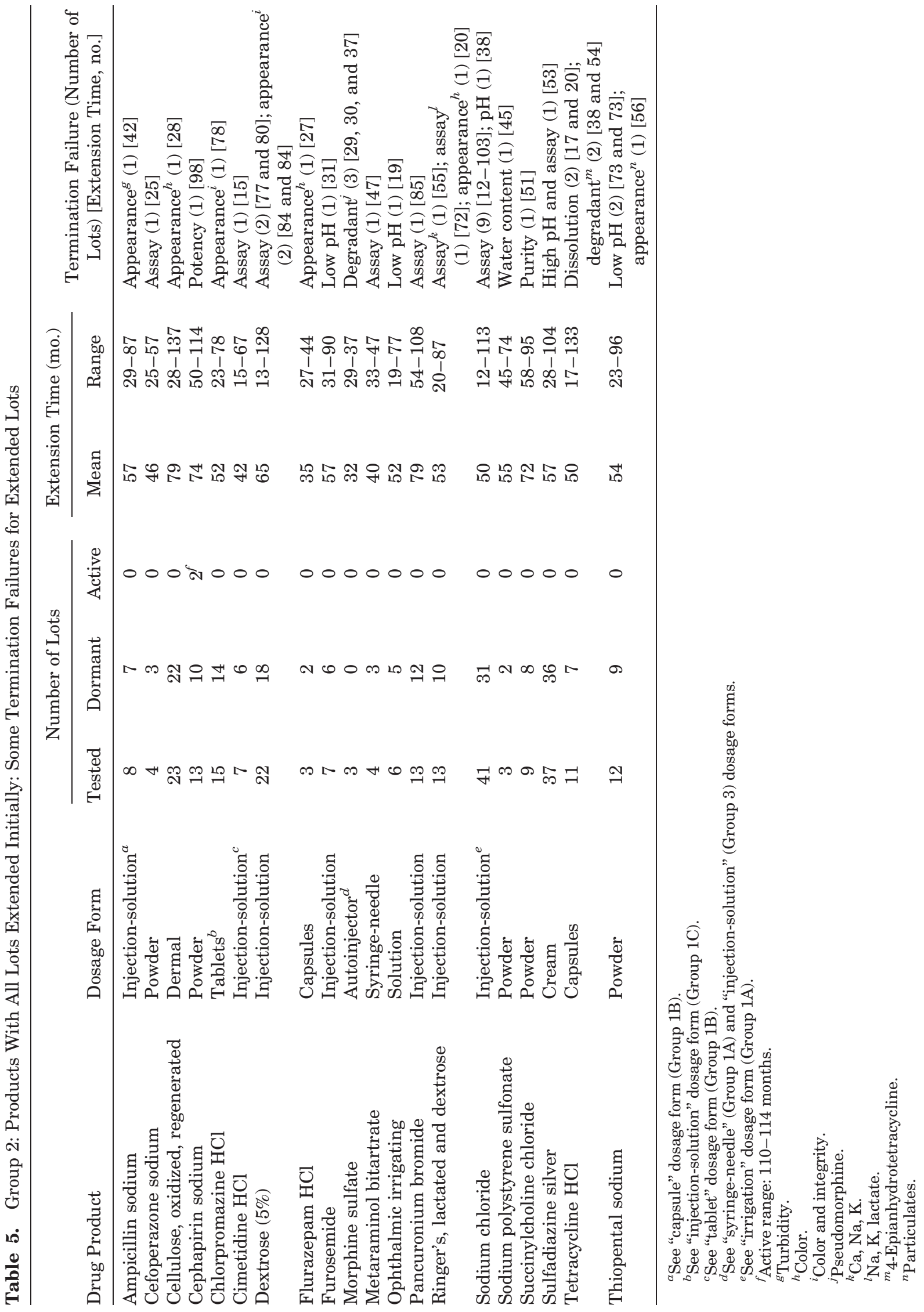




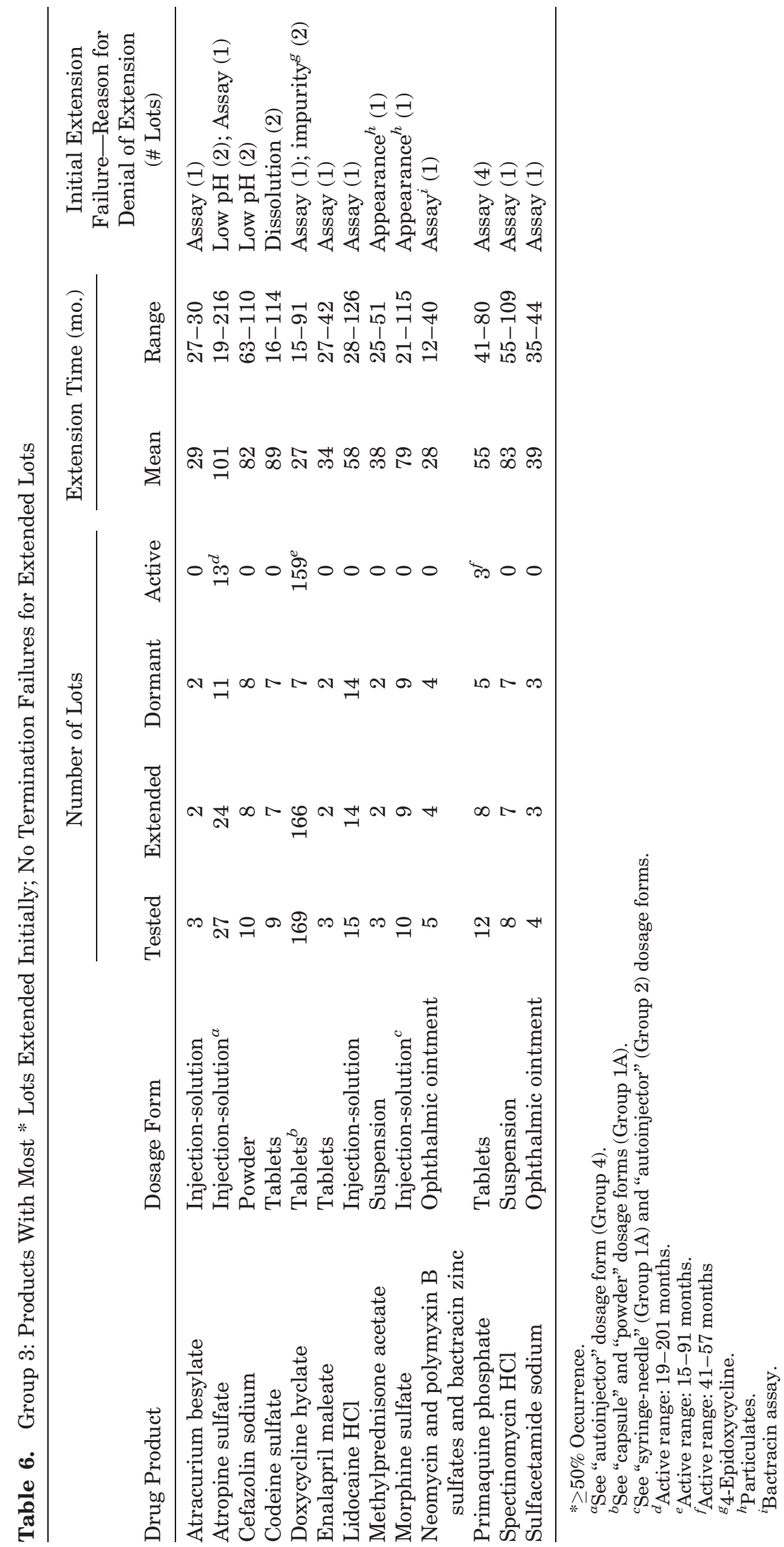




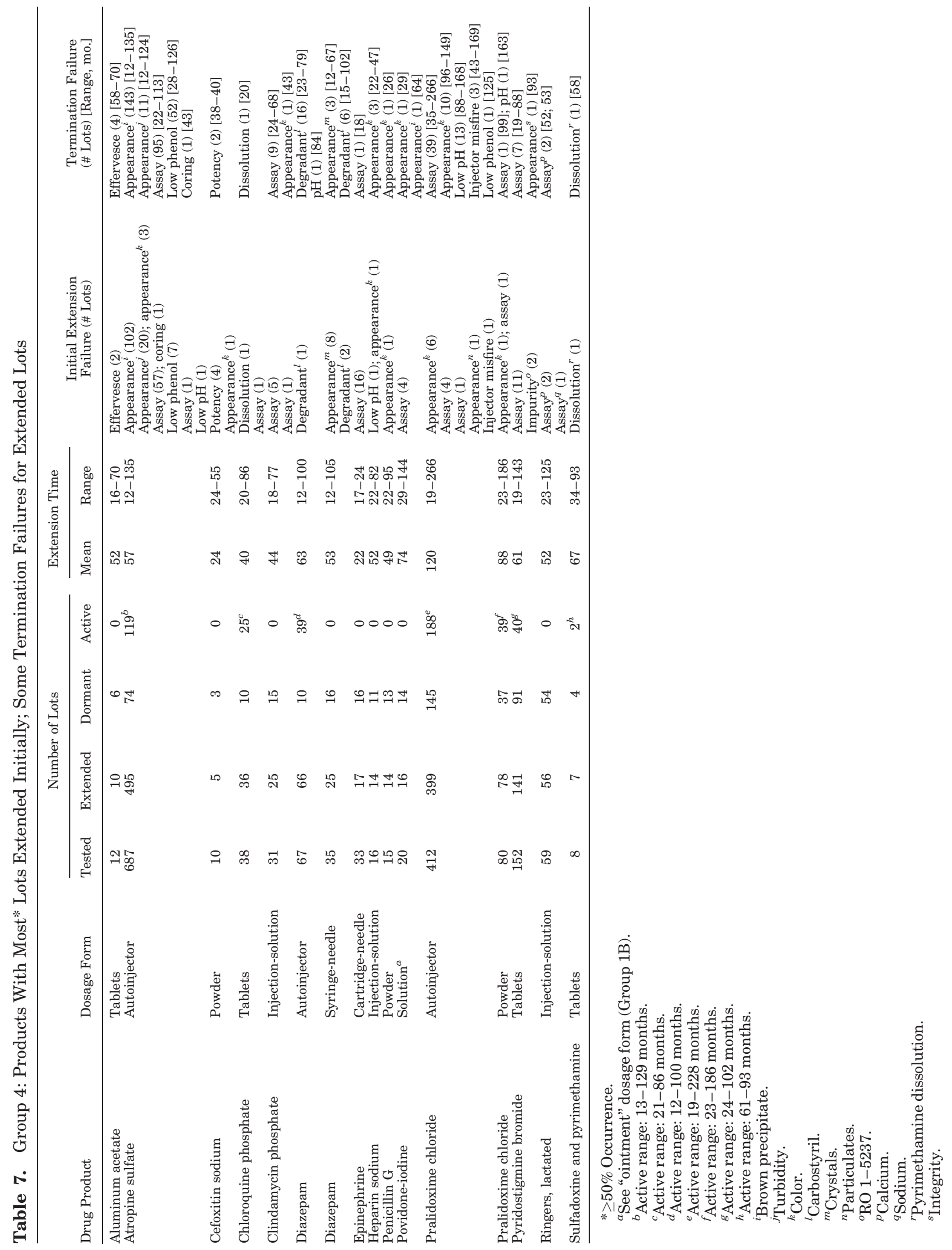




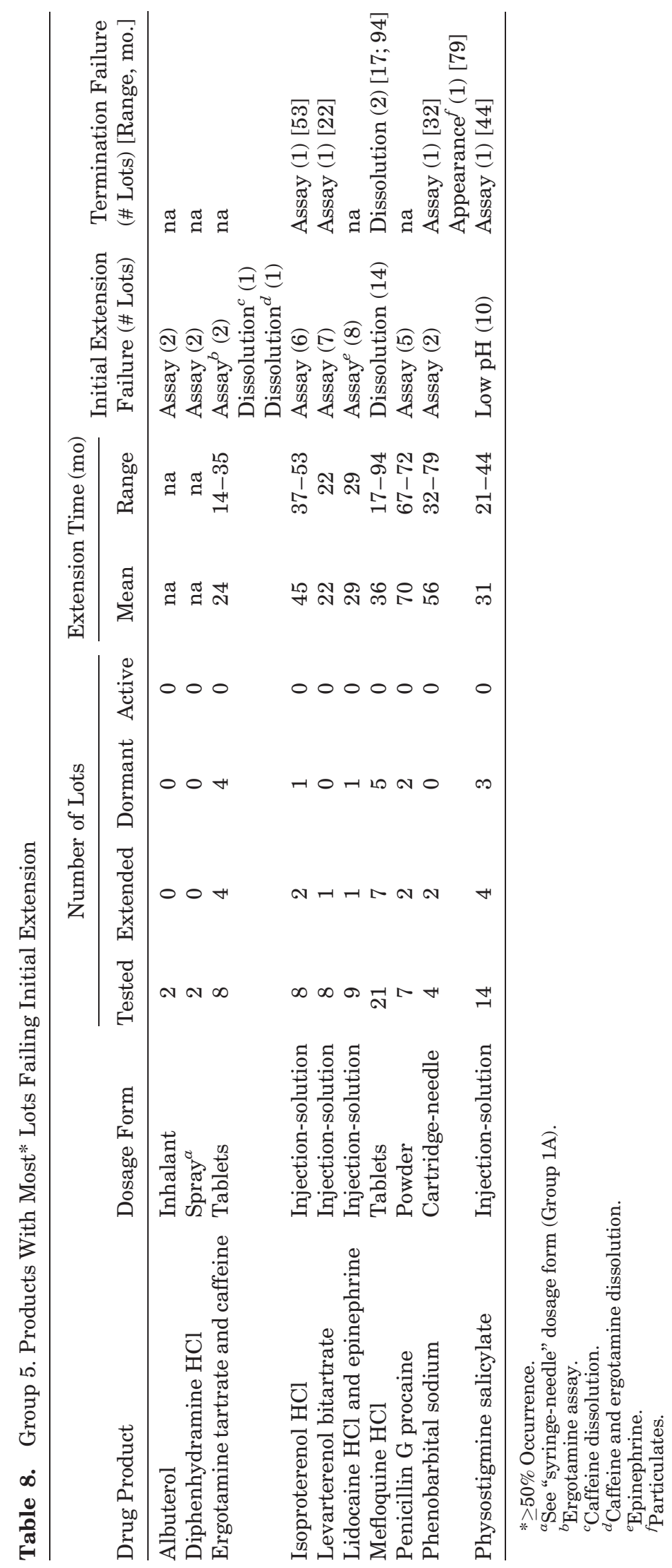


lots tested and the minimum extension time surpassed by all lots tested, need to be considered in evaluating the performance of these products. Group 1 was divided into 3 subgroups based on the number of lots tested. A greater confidence in the ability to extend the shelf life was associated with Group 1A ( $\geq 10$ lots tested). The most prolific performer from this subgroup was ciprofloxacin tablets (242 lots tested with 205 lots still active). Two other top performers from this group were naloxone $\mathrm{HCl}$ (all 10 lots extended at least 5 years) and halothane (all 12 lots extended over 4 years). The top performer in Group 1B was potassium iodide granules with all five lots still active nearly 20 years after the original expiration date. In addition, all of the lots of calcium chloride injection-solution and fentanyl citrate injectionsolution were extended more than 5 years. All of the lots of two products from Group 1C (bupivacaine $\mathrm{HCl}$ injection-solution and penicillin $\mathrm{G}$ benzathine suspension) were extended more than 5 years.

Although Group 2 had some lots that encountered termination failure, some of these products could be considered quite reliable. Examples from this group indicate that if products are stored long enough, failures are bound to occur. Of the products with $\geq 10$ lots tested, notable examples are listed. All of the cephapirin sodium powder lots (13 tested) were extended at least 4 years with only one termination, occurring at 8 years and all of the pancuronium bromide injection-solution lots (13 tested) were extended at least 4 years with only one termination, occurring at 7 years. In addition, sulfadiazine silver cream (37 lots tested) had only one termination, occurring after 4 years and dextrose injection-solution (23 lots tested) had four terminations, but all occurred after 8 years.

The products assigned to Group 3 had no termination failures, but for each product one to four lots failed initial extension, exemplifying lotto-lot variability. In some cases the extension times were quite long. Although two lots of cefazolin sulfate powder failed initial extension, the eight remaining lots were extended more than 5 years. One lot of spectinomycin sodium suspension failed initial extension, but the seven remaining lots were extended more than 4 years.

The products assigned to Group 4 had some lots exhibiting initial extension failure and some lots exhibiting termination failures. The lot-to-lot variability and the need for systematic testing were most evident with this group. This group includes products that have been extensively tested. The combination of lots from atropine sulfate autoinjectors (687 tested), pralidoxime chloride autoinjectors (412 tested), and pyridostigmine bromide tablets (152 tested) represents $42 \%$ of the total lots summarized in this report. Despite the failures, this group was relatively successful, considering 1404 (84\%) of the 1675 lots tested were initially extended. Diazepam autoinjectors (67 lots tested) had only one lot that failed initial extension and pralidoxime chloride powder (80 lots tested) had only two lots that failed initial extension. Of the extended pralidoxime chloride powder lots, only two were terminated, but these two lots were extended for more than 8 years. Other products were successfully extended including pralidoxime chloride autoinjectors (97\% of lots tested), lactated Ringers injection solution (95\%, 59 lots tested), and pyridostigmine bromide tablets (93\% of lots tested). The product exhibiting the greatest lot-to-lot variability was atropine sulfate autoinjectors. Hundred and ninety two lots (28\%) failed initial extension. The range of extension times for lots of atropine sulfate autoinjectors exhibiting termination failures was $1-11$ years.

For each of the 10 products assigned to Group 5, most of the lots could not be extended. Lot-to-lot variability was also evident with this group. Five of the seven penicillin $\mathrm{G}$ procaine powder lots could not be extended, while the other 2 lots were extended for more than 5 years. Fourteen of 21 mefloquine $\mathrm{HCl}$ tablets lots could not be extended, 1 extended lot was terminated at 17 months, while 1 lot was extended for more than 7 years. Of the 83 lots tested, only $28 \%$ could be initially extended. All of the products in this group were considered poor candidates and were discontinued from the shelf life program.

\section{Opportunity for Failures}

As more lots were tested, the chances that a lot would fail increased. This was reflected in the group classifications. Of the 27 products with 15 or more lots tested, 13 products are assigned to Group 4 compared to only 5 products assigned to Group 1A. Sulfadiazine silver, now assigned to Group 2, did not have any failures during the first 11 years on the program. Up until the termination failure of the 27th lot tested, this product was classified as Group 1A. Diazepam autoinjectors, now assigned to Group 4, did not have an initial extension failure during the first 6 years on the program. Up until the initial extension failure of the 48th lot tested, this product was classified as Group 2. Doxycycline 
tablets, now assigned to Group 3 did not have an initial extension failure during the first 6 years on the program. Up until the initial extension failure of the 13th lot, this product was classified as Group 1A. This illustrates that the group classifications may be dependent on the number of lots tested. This also supports the subclassification of Group 1 into $1 \mathrm{~A}, 1 \mathrm{~B}$, and $1 \mathrm{C}$.

\section{Other Programs}

The SLEP has been successful in helping to maintain drug reserves and reducing costs for the US Military. It is expected that similar programs will be implemented to preserve regional and national pharmaceutical stockpiles. One example is the SNS, formerly the National Pharmaceutical Stockpile, managed jointly by the Department of Homeland Security and the Department of Health and Human Services. ${ }^{10}$ The SNS Program ensures that the medical material stock is rotated and kept within potency shelf-life limits. The FDA has issued a shelf life extension guidance for federal agencies and state and local governments. A specific guidance was issued by CDER presenting FDA's recommendations on testing to extend the shelf life of stockpiled potassium iodide. ${ }^{11}$ This guidance describes how to identify laboratories suitable to conduct the tests, how to notify holders of stockpiled drug products and end users about changes in expiration date, and how to distinguish stockpiled batches with different expiration dates.

\section{CONCLUSION}

The SLEP data supports the assertion that many drug products can be extended past the original expiration date, but this additional stability period is highly variable. Due to the lot-to-lot variability, the stability and quality of extended drug products can only be assured by periodic testing and systematic evaluation of each lot. The results of this stability program can only be related to products that have been carefully stored in their original sealed container closures. The class groupings indicate past stability performance and do not guarantee future performance. The classification of products presented in this study could be used to select promising potential candidates for an extension program.

\section{ACKNOWLEDGMENTS}

The authors are grateful to Christopher D. Ellison of the Division of Product Quality Research for editorial assistance.

\section{REFERENCES}

1. Woods M. Drugs may outlast label date. Post-Gazette National Bureau. May 30, 2005. Available at: http:// www.post-gazette.com/pg/05150/512789.stm.

2. Cohen LP. Many medicines prove potent for years past their expiration dates. The Wall Street Journal. March 29, 2000.

3. Garamone J. Program extends drug shelf-life. American Forces Press Service. March 29, 2000 Available at: http://www.defenselink.mil/news/Mar 2000/n03292000_20003292.html.

4. American Medical Association. "Pharmaceutical Expiration Dates". Report 1 of the Council on Scientific Affairs (A-01). July 25, 2001. Available at: http://www.ama-assn.org/meetings/public/annual01/ csa_reports.pdf\#search $=$ 'Pharmaceutical\%20Expiration\%20Dates'.

5. Stark G, Fawcett JP, Tucker IG. 1997. A study of the stability of some commercial drug dosage forms beyond their expiration dates. Pharm J 258:637-640.

6. Regenthal R, Stefanovic D, Albert T, Trauer H, Wolf T. 2002. The pharmacologic stability of 35year old theophylline. Hum Exp Toxicol 21:343346.

7. Scholtissek C, Webster RG. 1998. Long-term stability of the anti-influenza A compoundsamantadine and rimantadine. Antiviral Res 38: $213-215$.

8. International Conference on Harmonization: "Guidance for Industry Q1A(R2) Stability Testing of New Drug Substances and Products." Available at: http://www.fda.gov/cder/guidance/5635fnl.pdf.

9. DOD-FDA Shelf Life Extension Program website. Available at: http://www.usamma.army.mil/html/ dodshelf.cfm.

10. Strategic National Stockpile website. Available at: http://www.bt.cdc.gov/stockpile/.

11. FDA: "Guidance for Federal Agencies and State and Local Governments Potassium Iodide Tablets Shelf Life Extension." Available at: http://www. fda.gov/cder/guidance/5666fnl.pdf. 